\title{
Implementing Waste Oils with Reclaimed Asphalt Pavement
}

\author{
P. Aghazadeh Dokandari ${ }^{1}$, D. Kaya ${ }^{2}$, B. Sengoz ${ }^{2}$, A. Topal ${ }^{2}$ \\ ${ }^{1}$ The Graduate School of Natural and Applied Sciences, Dokuz Eylul University \\ Izmir, Turkey \\ ${ }^{2}$ Department of Civil Engineering, Dokuz Eylul University \\ Izmir, Turkey
}

\begin{abstract}
The present asphalt pavement industry faces two major issues. These two major issues are the increasing demand for ecofriendly asphalt mixtures and the costs of raw materials. The use of reclaimed asphalt pavement will be an essential attempt to reduce the costs of aggregates and bitumen in the final mixture. On the other hand, the main challenge for implementing RAP (Reclaimed Asphalt Pavement) is to overcome quality issues. RAP doesn't perform like a fresh pavement since it is an aged material and needs to be improved. This puts forward the requirement for extra practices like using of rejuvenating agents. Since bitumen loses its oily constituents when it ages, the use of oil-containing additives can be effective. In this study, two kinds of waste oils were used to rejuvenate aged asphalt mixture. Optimum contents of Waste Engine Oil (WEO) and Waste Vegetable Oil (WVO) additives were determined in order to implement various RAP contents. The effects of these two oily based rejuvenators on utilization of RAP in bituminous mixtures were investigated. The results represented that the use of WEO and WVO as rejuvenators for mixtures containing RAP enhances the amount of RAP used in bituminous mixtures.
\end{abstract}

Keywords: Asphalt Recycling, Reclaimed Asphalt Pavement, Rejuvenator, Waste Engine Oil, Waste Vegetable Oil

\section{Introduction}

Due to increased environmental awareness and limited resources, researchers are seeking for new methods and technologies to ensure sustainability, efficiency and less greenhouse gases in asphalt industry. In recent years, reutilizing of materials has been on the forefront of new technologies particularly in construction sector. Reclaimed Asphalt Pavement (RAP) is aged pavement materials reclaimed to be utilized over. In road construction industry, the utilization of recycled asphalt pavement (RAP) in hot bituminous mixtures can relief the manic use of natural resources and as a matter of course can cause less damage to our nature [1]. There are also other areas of implementation for RAP in construction sector. RAP can be used as embankment material, but also as aggregates in hot and cold recycling technologies [1]. Cold recycling of bituminous mixtures involves RAP, water and a recycling agent without applying heat generally by use of emulsions, since hot recycling implements recycling agents in presence of heat. Both hot and cold recycling methods can be carried out at a production plant or in situ. The common point in both recycling methods is the presence of a recycling agent utilized to make the application more convenient and to enhance the quality.

RAP is consisted of aggregates and bitumen. By use of RAP, less new hot mix will be required for a unit length of a typical road. In this regard, not only the saving of raw materials will be possible, but also it will contribute in saving of energy and less emission of hazardous gases. Saving aggregates, bitumen and energy will bring in economic and ecological benefits to asphalt industry. The more the use of RAP, the more benefit can be gained via recycling [2]. This is the main reason for all efforts to make $100 \%$ recycling of pavement materials possible.

The most essential challenge in use of high amounts of RAP is to overcome quality issues. Since RAP is basically aged material, it cannot be directly added to hot mixture without any extra attempt to enhance its properties. Accordingly several methods have been developed by private sector in order to use high quantities of RAP within bituminous mixtures without facing quality issues [3]. However many of these methods are not accessible by the public because of know-how concerns and/or intellectual property protection laws. Utilization of rejuvenators also called recycling agents is one of the most current methods introduced to facilitate the use of RAP especially within the upper surfaces of flexible pavements such as binder and surface courses [4]. We all know that the aging of bitumen in the course of time occurs due to several reasons. Meanwhile, the most important characteristic of aged bitumen is the lack of oily components [5]. This has 
prompted researchers to restore the freshness of the aged bitumen by means of oily based additives. Various kinds of rejuvenators have been introduced to asphalt recycling industry so far, some commercialized and some still remained within the scientific literature. Bitumen is basically defined as a colloid system in which the asphaltenes take role as the dispersed phase and the maltenes as the continuous phase [6]. The evaporation and removal of oily constituents (mostly the maltenes) has an important share in aging process of bitumen [7]. Therefore, there is an intuitive idea that without using rejuvenators, recycling results in brittle and stiffer pavement with less flexibility [8]. The use of rejuvenators is the most referenced practice for utilization of RAP within the literature. The key literatures compiled from recent studies and practices are presented in the following paragraphs.

Shen et al. (2007) evaluated the utilization of rejuvenating agents on Superpave mixtures containing RAP. It is reported that the mechanical properties of mixtures involving RAP and the rejuvenating agent were improved. Additionally, more amount of RAP could be included within the Superpave mixtures by use of oily based rejuvenators [9].

Asli et al. (2012) investigated the feasibility of waste cooking oil as a rejuvenator in recycled mixtures. Authors indicated that the use of waste cooking oil rehabilitated the properties of aged bitumen. It is said that the rejuvenated bitumen behaved similar to virgin bitumen in terms of penetration and softening point. The researchers also claimed more amount of RAP within the recycled mixtures could be accessible by implementation of waste cooking oil [10].

Yu et al. (2014) implemented waste vegetable oil and an aromatic extract in order to rejuvenate the aged bitumen. The rejuvenator was used to enhance the rheological properties of the aged bitumen. It is reported that the use of these agents could modify the chemical structure of the aged bitumen and thus the mechanical behaviour of the mixtures. The researchers evaluated the samples at both macro- and micro-scales and found out that the characterization of rejuvenating impact on the aged bitumen could gain the advantage of improved recycling for bituminous materials [11].

In another study, high temperature properties of bitumen rejuvenated with waste cooking and cotton seed oil was examined [12]. The authors reported that use of these rejuvenators could reduce the viscosity value of bitumen. The fail temperature of rejuvenated bitumen also was decreased. Besides, the rheological studies unveiled that the phase angle rejuvenated bitumen increased. Based on the results, the adequate dosage of rejuvenator can recover the rutting performance of aged bitumen substantially [12].

Ongel and Hugener (2015) also discovered that the use of rejuvenators can recover the original rheological properties of aged bitumen to a large extent. The authors claimed that $100 \%$ recycling can be a solution for environmental problems under favour of rejuvenators [13].

Nayak and Sahoo (2015) tried two kinds of local oil for rejuvenating of aged bitumen. Panogamia oil and composite castor oil were employed within this study. The rheological evaluation of effect of rejuvenators on aged bitumen represented that, these oils are capable of enhancing both rutting and fatigue properties of aged bitumen [14].

When it comes to Waste Engine Oil (WEO), what literature survey brings to light is that WEO is also amongst the addressed oily based rejuvenators [15], [16]. Zaumanis et al. investigated the performance properties of RAP bitumen and $100 \%$ recycled asphalt mixtures with six different rejuvenators. WEO was employed in order to enhance RAP bitumen within the study. The authors reported improvement in many aspects such as reducing the performance grade of the rejuvenated RAP bitumen to the level of virgin bitumen, passing rutting requirement, enhancing of mixture cracking resistance and an improved workability for rejuvenated mixtures [15].

WEO was similarly employed within another study conducted by Jia et al. (2015) aiming to investigate its influence on the rheological properties of RAP bitumen as well as fatigue properties of HMA containing RAP. It was reported that the use of WEO within HMA involving RAP can offset the increase of stiffness imposed by aged RAP bitumen. The authors claimed limited enhancements on fatigue properties of the mixtures containing WEO rejuvenated RAP [16].

Ji et al. (2016) within a study tried to recover the aged asphalt (extracted from RAP materials) by use of two waste cooking vegetable oil rejuvenators (corn oil and soybean oil). They aimed to replace these light oil components with better temperature resistance with heavy oils. They compared the effectiveness of these waste cooking vegetable oils with a heavy oily rejuvenator and a commercial rejuvenator in different ratios. The study shows that the by use of these waste cooking vegetable oils the aged asphalt binder viscosity and stiffness decrease. The fatigue and low-temperature cracking resistance improves significantly by use of these rejuvenators [17].

Gong et al. (2016) showed that Bio-oil can be used to rejuvenate aged bitumen. They observed that the physical characteristic of aged asphalt is enhanced via mixing with bio-oil [18]. 
Sun et al. (2016) implemented a kind of bio-oil derived from waste cooking oil into aged bitumen as rejuvenator. They investigated the chemical compositions of bio-oil and control specimen. They reported that bio-oil contribute in reducing of the deformation resistance and in improving of the stress relaxation property of control bitumen samples [19].

\section{Materials and Methods}

\subsection{Materials}

The virgin bitumen with a 50/70 penetration grade obtained from Aliaga/Izmir Oil Terminal of Turkish Petroleum Refinery Corporation was used in this study. In order to characterize the properties of the virgin bitumen, conventional test such as: penetration test, softening point test, ductility test, etc. were performed. These tests were conducted in conformity with the relevant test methods that are presented in Table 1.

Table 1: Properties of virgin bitumen.

\begin{tabular}{|c|c|c|c|}
\hline Test & Specification & Results & Specification limits \\
\hline Penetration $\left(25^{\circ} \mathrm{C} ; 0.1 \mathrm{~mm}\right)$ & TS EN 1426 & 63 & $50-70$ \\
\hline Softening point $\left({ }^{\circ} \mathrm{C}\right)$ & TS EN 1427 & 49.7 & $46-54$ \\
\hline Viscosity at $\left(135^{\circ} \mathrm{C}\right)$-Pa.s & ASTM D4402 & 0.425 & - \\
\hline Viscosity at $\left(165{ }^{\circ} \mathrm{C}\right)$-Pa.s & ASTM D4402 & 0.1 & - \\
\hline Rolling Thin Film Oven $\left(163{ }^{\circ} \mathrm{C}\right)$ & TS EN 12607-1 & & $0.5(\max )$ \\
\hline Change of mass $(\%)$ & & 0.05 & $50(\mathrm{~min})$ \\
\hline Retained penetration after RTFO $(\%)$ & TS EN 1426 & 74 & 7 (max) \\
\hline Softening point rise after RTFO $\left({ }^{\circ} \mathrm{C}\right)$ & TS EN 1427 & 4.5 & - \\
\hline Specific gravity & ASTM D70 & 1.038 & $230(\mathrm{~min})$ \\
\hline Flash point $\left({ }^{\circ} \mathrm{C}\right)$ & TS EN 22592 & +260 & \\
\hline
\end{tabular}

The asphalt mixtures were produced using limestone aggregates. Fine and coarse limestone aggregates were procured from Dere Madencilik/Izmir quarry. In order to determine the properties of the limestone aggregate, sieve analysis, specific gravity, Los Angeles abrasion resistance test, sodium sulfate soundness test, fine aggregate angularity test and flat \& elongated particles tests were conducted on the aggregates. The results are presented in Table 2. Grading of aggregate was chosen in conformity with the Type I Wearing Course of Turkish Specifications. Table 3. applies to the final gradation.

Table 2: Properties of limestone aggregate.

\begin{tabular}{|c|c|c|c|}
\hline Test & Specification & Result & Specification limits \\
\hline Specific Gravity (Coarse Agg.) & ASTM C 127 & & - \\
\hline Bulk & & 2.704 & - \\
\hline SSD & & 2.717 & - \\
\hline Apparent & & 2.741 & - \\
\hline Specific Gravity (Fine Agg.) & ASTM C 128 & & - \\
\hline Bulk & & 2.691 & - \\
\hline
\end{tabular}

Table 2 Properties of limestone aggregate (cont.)

\begin{tabular}{|c|c|c|c|}
\hline Test & Specification & Result & Specification limits \\
\hline SSD & & 2.709 & - \\
\hline Apparent & & 2.739 & - \\
\hline Specific Gravity (Filler) & & 2.732 & - \\
\hline Los Angeles Abrasion (\%) & ASTM C 131 & 22.6 & Max. 30 \\
\hline Flat and Elongated Particles (\%) & ASTM D 4791 & 7.5 & Max. 10 \\
\hline Sodium Sulphate Soundness (\%) & ASTM C 88 & 1.47 & Max. 10-20 \\
\hline Fine Aggregate Angularity & ASTM C 1252 & 47.85 & Min. 40 \\
\hline
\end{tabular}


Table 3: Gradation Table.

\begin{tabular}{|c|c|c|c|}
\hline Sieve Size/No. & Gradation $(\%)$ & Specification & Specification Limits (\%) \\
\hline $19 \mathrm{~mm}$. & 100 & \multirow{8}{*}{$\begin{array}{c}\text { Type I Wearing } \\
\text { Course } \\
\text { (Turkish } \\
\text { Specification) }\end{array}$} & 100 \\
\hline $12.5 \mathrm{~mm}$. & 92 & & $83-100$ \\
\hline $9.5 \mathrm{~mm}$. & 73 & & $70-90$ \\
\hline No.4 & 44.2 & & $40-55$ \\
\hline No.10 & 31 & & $25-38$ \\
\hline No.40 & 12 & & $10-20$ \\
\hline No.80 & 8 & & $6-15$ \\
\hline No.200 & 5.3 & & $4-10$ \\
\hline
\end{tabular}

Reclaimed type I wearing surface course subjected to traffic loads for a period of 12 years was used as RAP. $16 \mathrm{x}$ 1000 gr. of batch samples were selected randomly using a random separator. The bitumen content and gradation of RAP materials were determined. The bitumen of the aged asphalt was extracted and distilled using a laboratory type extractor and distillatory. According to the test results, the bitumen content of the RAP was found $4.30 \%$. As a final point, sieve analysis performed on the extracted aggregates. The results are given in Table 4 . The conventional bitumen tests were conducted to the extracted bitumen of RAP. The results for the extracted bitumen are presented within Table 5.

Table 4: Sieve analysis of RAP aggregates.

\begin{tabular}{|c|c|c|c|}
\hline Sieve No & Retained (\%) & Passing (\%) & Spec. Limits (\%) \\
\hline $19 \mathrm{~mm}$. & 0 & 100 & 100 \\
\hline $12.5 \mathrm{~mm}$. & 1.6 & 98.4 & $83-100$ \\
\hline $9.5 \mathrm{~mm}$. & 10.1 & 89.9 & $70-90$ \\
\hline No.4 & 45.9 & 54.1 & $40-55$ \\
\hline No.10 & 69.8 & 30.2 & $25-38$ \\
\hline No.40 & 86.5 & 13.5 & $10-20$ \\
\hline No.80 & 91.18 & 8.82 & $6-15$ \\
\hline No. 200 & 94.17 & 5.83 & $4-10$ \\
\hline
\end{tabular}

Table 5: Properties of RAP bitumen.

\begin{tabular}{|c|c|c|}
\hline Test & Specification & Results \\
\hline Penetration $\left(25^{\circ} \mathrm{C} ; 0.1 \mathrm{~mm}\right)$ & TS EN 1426 & 38 \\
\hline Softening point $\left({ }^{\circ} \mathrm{C}\right)$ & TS EN 1427 & 61 \\
\hline Viscosity at $\left(135^{\circ} \mathrm{C}\right)$-Pa.s & ASTM D4402 & 0.538 \\
\hline Viscosity at $\left(165^{\circ} \mathrm{C}\right)$-Pa.s & ASTM D4402 & 0.188 \\
\hline
\end{tabular}

The waste engine oil that will be used as a rejuvenator was provided from varies industrial organizations and waste vegetable oil was obtained from retail stores who owns the license for collection of waste oils.

\subsection{Methodology}

Within the scope of this study, the effect of two different kinds of waste oils (WEO, WVO) was evaluated on aged bitumen. These rejuvenators were used to increase the applicable amount of RAP in bituminous mixture. Rejuvenated asphalt specimens were produced using a laboratory Marshall compactor according to Marshall mix design method. Marshall stability and flow test were employed in order to determine the mechanical properties. The volumetric analysis was used as criteria in selection of highest amount of RAP within the mixtures. Control and rejuvenated samples were measured and controlled as per Turkish Specification limits. Subsequently, the specimens containing highest RAP contents 
were prepared in order to define Indirect Tensile Strength (ITS) values. Finally, ITS values were taken into consideration in calculation of aging indices of both WEO and WVO rejuvenated specimens with highest RAP contents. The results were used to make comparisons in terms of stiffness.

Two main steps were followed in design of asphalt specimens with different amount of RAP; at the first step, the material properties were determined and at the second step, the content of RAP and virgin materials (aggregates and binder) were defined. Appropriate ratios of RAP to virgin materials in target mixtures were defined considering the overall properties of RAP and virgin materials.

\subsubsection{Determination of target mixtures contents}

As the primary step; the optimum bitumen content of the control mixtures was determined as $4.76 \%$. The Marshall Mix design criteria corresponding to $4 \%$ air void was taken into consideration in determination of optimum bitumen content for control mixtures. The amount of virgin bitumen and aggregates in target mixtures which depend on the percentage of RAP supposed to be added to the target mixture was calculated separately for different RAP contents. The amount of virgin bitumen to be added to the target mixture was calculated taking Eq. (1) into account.

$$
\operatorname{Pr}=\mathrm{Pc}-(\mathrm{Pa} \cdot \mathrm{Pp})
$$

where;

Pr: Percent of virgin bitumen to be added in the mix containing RAP

Pa: Percent of RAP bitumen in the mix

Pc: Percent of total bitumen in the mix

Pp: Percentage of RAP in the mix

The target bitumen amounts supposed to be added to the total mixture were calculated using Eq. (1). These values are given in Table 6. Following the calculation of virgin bitumen and aggregates amounts, mixing and compaction temperatures of rejuvenated and control specimens were calculated as per equiviscous temperature charts. Temperature charts for the virgin and rejuvenated bitumen were plotted on graphs taking the viscosity values at $135^{\circ} \mathrm{C}$ and $165^{\circ} \mathrm{C}$ into consideration. Viscosity values were measured by means of a Brookfield viscometer.

Table 6: Bitumen contents to be added into the target mixes.

\begin{tabular}{|c|c|c|c|}
\hline RAP Content (\%) & $\operatorname{Pc}(\%)$ & $\mathrm{Pa}(\%)$ & $\operatorname{Pr}(\%)$ \\
\hline 10 & \multirow{5}{*}{4.76} & \multirow{5}{*}{4.30} & 4.33 \\
\hline 20 & & & 3.9 \\
\hline 30 & & & $\begin{array}{l}3.47 \\
\end{array}$ \\
\hline 40 & & & 3.04 \\
\hline 50 & & & 2.61 \\
\hline 60 & \multirow{5}{*}{4.76} & \multirow{5}{*}{4.30} & 2.18 \\
\hline 70 & & & $\begin{array}{l}1.75 \\
\end{array}$ \\
\hline 80 & & & 1.32 \\
\hline 90 & & & 0.89 \\
\hline 100 & & & 0.46 \\
\hline
\end{tabular}

\subsubsection{Determining optimum rejuvenator content and rejuvenation process}

Considering the conventional bitumen test results for virgin and RAP bitumen, the objective was defined as to rejuvenate RAP binder in order to obtain a binder similar to virgin binder in terms of specifications. A rejuvenating agent is supposed to enhance and cure the RAP binder in terms of physical and chemical properties. Several studies address the penetration value as an indicator for determining the optimum rejuvenator content [10], [20]-[22].

Within the study, the optimum rejuvenator content was determined as the content required to achieve a rejuvenated binder having the same penetration value of the virgin binder. In other words, when the RAP binder is modified with that percentage of rejuvenator, the acquired binder should have the same penetration value of virgin binder. In order to perform this task, RAP binder was modified with various ratios of WEO and WVO. The range was chosen based on literature 
review and preliminary studies [16]. Modification was processed for 5 minutes at $140{ }^{\circ} \mathrm{C}$ using a laboratory blender at normal shear rates $(700 \mathrm{rpm})$ to obtain a homogenous rejuvenated binder. Table 7 represents the penetration test results of rejuvenated binders with various WEO and WVO contents. The optimum WEO content was determined as $5.4 \%$ by weight of RAP binder corresponding target penetration value of 63 and for WVO, the optimum content was defined to be $5.1 \%$.

Following the determination of optimum WEO and WVO contents; RAP mixtures were rejuvenated and stored. In order to perform the rejuvenation process, 4000 gr batches of RAP were heated to $140^{\circ} \mathrm{C}$, the temperature at which the binder blending was processed. The bitumen content of RAP were calculated and taken into account in rejuvenation process. Within the process, the optimum amount of rejuvenating additive was gradually sprayed into the mixture during mixing inside a laboratory mixer for 5 minutes. The obtained rejuvenated RAP had a shining dark brown colour compared to non-rejuvenated RAP.

Table 7: Penetration values for rejuvenated binders by various WEO and WVO contents.

\begin{tabular}{|c|c|c|}
\hline \multirow{2}{*}{ Rejuvenator Content $(\%)$ by weight of RAP binder } & \multicolumn{2}{|c|}{ Penetration $\left(25^{\circ} \mathrm{C} ; 0.1 \mathrm{~mm}\right) \mathrm{TS}$ EN 1426} \\
\cline { 2 - 3 } & WEO & WVO \\
\hline 0 & 38 & 38 \\
\hline 2 & 44.5 & 45,2 \\
\hline 3 & 49 & 50,3 \\
\hline 4 & 53.5 & 55,1 \\
\hline 5 & 59.5 & 62 \\
\hline 6 & 68 & 69,7 \\
\hline
\end{tabular}

\subsubsection{Indirect tensile strengths and aging evaluation of mixtures}

Following the determination of highest possible RAP contents by use of WEO and WVO, specimens were prepared with these highest RAP contents for both rejuvenated and non-rejuvenated mixtures. The specimens were tested for Indirect Tensile Strength (ITS) accordingly. To perform the task, ASTM D6931 the standard test method for indirect tensile strength of bituminous mixtures followed. The ITS test was conducted using a Marshall stability and flow apparatus. The loading rate set to $51(\mathrm{~mm} / \mathrm{min})$ in case for ITS.

To be adequate and unbiased, three specimens of both non-rejuvenated and rejuvenated mixtures as well as control specimens (with no RAP content) were prepared and tested. The ITS results provide an evaluation criteria in terms of low temperature and fatigue cracking of asphalt pavements. Some studies introduce ITS as a good indicator in predicting laboratory rutting potential of asphalt mixtures [23]. This test is widely used in investigation of moisture induced damages of bituminous mixtures.

It is known that, aged binder is more brittle and stiffer. In order to evaluate the aging characteristics of nonrejuvenated and rejuvenated mixtures, the ITS results of mixtures involving RAP were compared to the results of control mixtures with no RAP. Aging indices were obtained to investigate the aging characteristics of asphalt mixtures. Sengoz (2003) implemented ITS in order to assess the aging and moisture susceptibility of HMA mixtures with various air void contents [24]. Another study on short- and long-term aging behaviour of rubber modified asphalts conducted by Liang and Lee (1996) showed that the aging causes the increasing of tensile strengths [25]. Sengoz and Topal (2008) investigated the effects of SBS polymer modified bitumen on the aging properties of asphalt mixtures using ITS results [26]. They took aging indices as the ratio of short- and long-term aged specimen's ITS values to the values of un-aged control specimens. Hurley and Prowell (2005) used ITS results to assess the rutting potential after applying short- and long-term aging processes on WMA mixtures [27].

The raw data recorded from the test device are to be processed using the following Eq. (2) to obtain indirect tensile stresses:

$$
S_{t}=\frac{2000 \times P}{\pi \times t \times D}
$$

Where;

$\mathrm{St}=$ Indirect tensile strength (ITS), $\mathrm{kPa}$ 
$\mathrm{P}=$ Maximum load, $\mathrm{N}$

$\mathrm{t}=$ Specimen height immediately before test, $\mathrm{mm}$

$\mathrm{D}=$ Specimen diameter, $\mathrm{mm}$

Following the determination of ITS values, the aging indices were calculated by dividing ITS values of nonrejuvenated and rejuvenated mixtures over ITS values of non-aged (virgin) control specimens.

\section{Results and Discussion}

\subsection{Binder test results}

Results for rejuvenated binder with optimum WEO and WVO content are presented in Table 8. The test results represented that the oily based additives are capable of increasing penetration values of aged bitumen. Then again, by using these rejuvenators the softening point values can be lowered to the specification limits. Fig 1 represents the penetration values for various contents of WEO and WVO rejuvenators. The optimum additive content was derived from the chart choosing the content corresponding the same penetration value of the virgin binder. As seen on the Fig. 1, the penetration values track an increasing polynomial trend-line as rejuvenator content increases. It is possible to gain a desired penetration by adding adequate content of WEO and/or WVO to RAP binder. The results for WEO and WVO were similar to each other in terms of penetration. WVO represented slightly higher values than WEO in terms of penetration. This can be attributed to the viscosity values of two oily based rejuvenators. After modifying aged bitumen by rejuvenators, the softening point must be controlled as per specification limits. Also the rejuvenated bitumen must be controlled in line with other specifications such as change of mass value and the retained penetration after Rolling Thin Film Oven Test (RTFOT). Volatilization of oily based rejuvenators during production phase is a concerned issue in using of rejuvenators. The value of mass change and the retained penetration after RTFOT is a decent indicator for this issue. Both WEO and WVO have acceptable temperature resistance to volatilization. Ji et al. indicated in their study that the heavy fuel oils are sensitive to volatilization and at high recycling temperature (over $180^{\circ} \mathrm{C}$ ) disappear from the mixture and accordingly this causes to less RAP materials in total mixture. They suggested that vegetable oils are rich in unsaturated fatty acids and are similar to light oils resist better against volatilization [15]-[17]. Although the results after RTFOT were with the specification limits, the results proved that the rejuvenated binders are more sensitive to short term aging than virgin binder.

Furthermore, the viscosity values showed that the workability of rejuvenated RAP mixtures improved significantly. Mixing and compaction of rejuvenated mixtures were made with a regular effort. Softening point values of rejuvenated samples were more than softening point of virgin binder. Although these values are around the borderline value in terms of specifications, it can be concluded that the rejuvenated bitumen can endure higher temperatures during hot seasons. The rejuvenated binders behave similar to air-blown asphalts in this case.

Table 8: Properties of rejuvenated RAP binder modified with optimum WEO content.

\begin{tabular}{|c|c|c|c|c|}
\hline \multirow{2}{*}{ Test } & \multirow{2}{*}{ Specification } & \multicolumn{2}{|c|}{ Results } & \multirow{2}{*}{$\begin{array}{c}\text { Specification } \\
\text { limits }\end{array}$} \\
\hline & & WEO $(5.4 \%)$ & WVO $(5.1 \%)$ & \\
\hline Penetration $\left(25^{\circ} \mathrm{C} ; 0.1 \mathrm{~mm}\right)$ & TS EN 1426 & 63 & 63 & $50-70$ \\
\hline Softening point $\left({ }^{\circ} \mathrm{C}\right)$ & TS EN 1427 & 54 & 55.3 & $46-54$ \\
\hline Viscosity at $\left(135^{\circ} \mathrm{C}\right)-\mathrm{Pa} . \mathrm{s}$ & ASTM D4402 & 0.412 & 0.400 & - \\
\hline Viscosity at $\left(165^{\circ} \mathrm{C}\right)-\mathrm{Pa} . \mathrm{s}$ & ASTM D4402 & 0.087 & 0.075 & - \\
\hline Rolling Thin Film Oven $\left(163^{\circ} \mathrm{C}\right)$ & TS EN 12607-1 & & & \\
\hline Change of mass $(\%)$ & & 0.12 & 0.1 & $0.5(\max )$ \\
\hline Retained penetration after RTFO (\%) & TS EN 1426 & 53 & 59 & $50(\mathrm{~min})$ \\
\hline Softening point rise after RTFO $\left({ }^{\circ} \mathrm{C}\right)$ & TS EN 1427 & 6 & 5 & $7(\max )$ \\
\hline
\end{tabular}




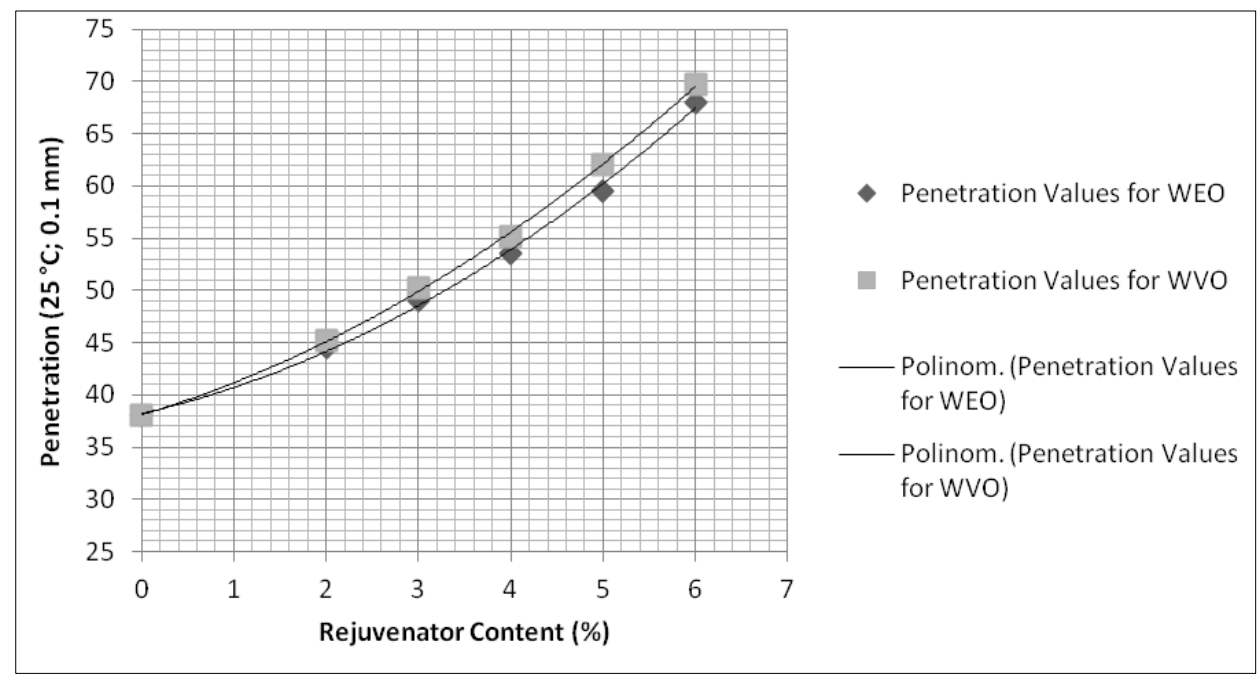

Fig. 1: Penetration values corresponding various contents of WEO and WVO.

\subsection{Mixture test results}

As mentioned before, the highest RAP contents were determined for mixture containing non-rejuvenated and rejuvenated RAP in order to compare the highest potential of RAP to be employed within a type I wearing course.

Marshall stability and flow results

Volumetric analysis together with Marshall stability and flow values were base criteria in selection of maximum possible RAP content for both mixture involving non-rejuvenated and rejuvenated RAP. Results for air void contents, stabilities and flow rates are respectively presented in Fig. 2 to Fig. 4 for WEO and WVO rejuvenated specimens as well as control specimens.

As can be seen in the Fig. 2, all mixtures containing rejuvenated RAP could meet volumetric criteria in terms of air voids since mixtures containing non-rejuvenated RAP fail to satisfy desired air voids content for mixtures containing more than $40 \%$ of non-rejuvenated RAP. The reason that volumetric characteristic of rejuvenated RAP containing mixtures remained within the desired contents is attributed to lower viscosity values of rejuvenated RAP binder and hence improved workability. At standard mixing and compaction temperatures, it is more convenient to process WEO and WVO rejuvenated RAP mixtures than non-rejuvenated RAP mixtures. Vegetable based oil performed better than engine oil in terms of softening the stiff RAP materials. This is in parallel with the result of penetration test. This can be attributed to higher resistance of vegetable based oils to volatilization during production (mixing \& compaction) phase at high temperatures.

When Fig. 3 is analysed, it is seen that all stability values are over specification limit. This result is expected since the bitumen within RAP is considered as an aged binder and thus the mixtures containing RAP are stiffer than virgin bituminous mixtures hence these mixtures recorded high stabilities. In fact, the most concerned issue for RAP recycling technologies is considered as durability rather than stability. Therefore, volumetric characteristics and flow rates (somehow, as an indicator of flexibility) are more determinative for maximum possible RAP content than stability values. 


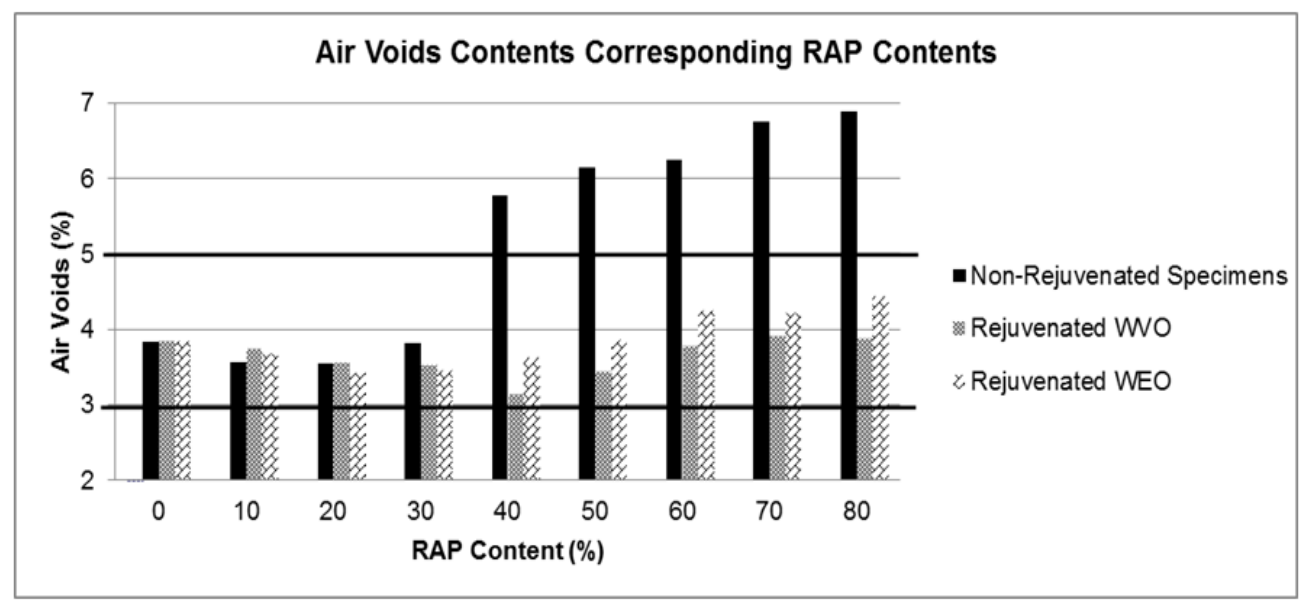

Fig. 2: Air void contents.

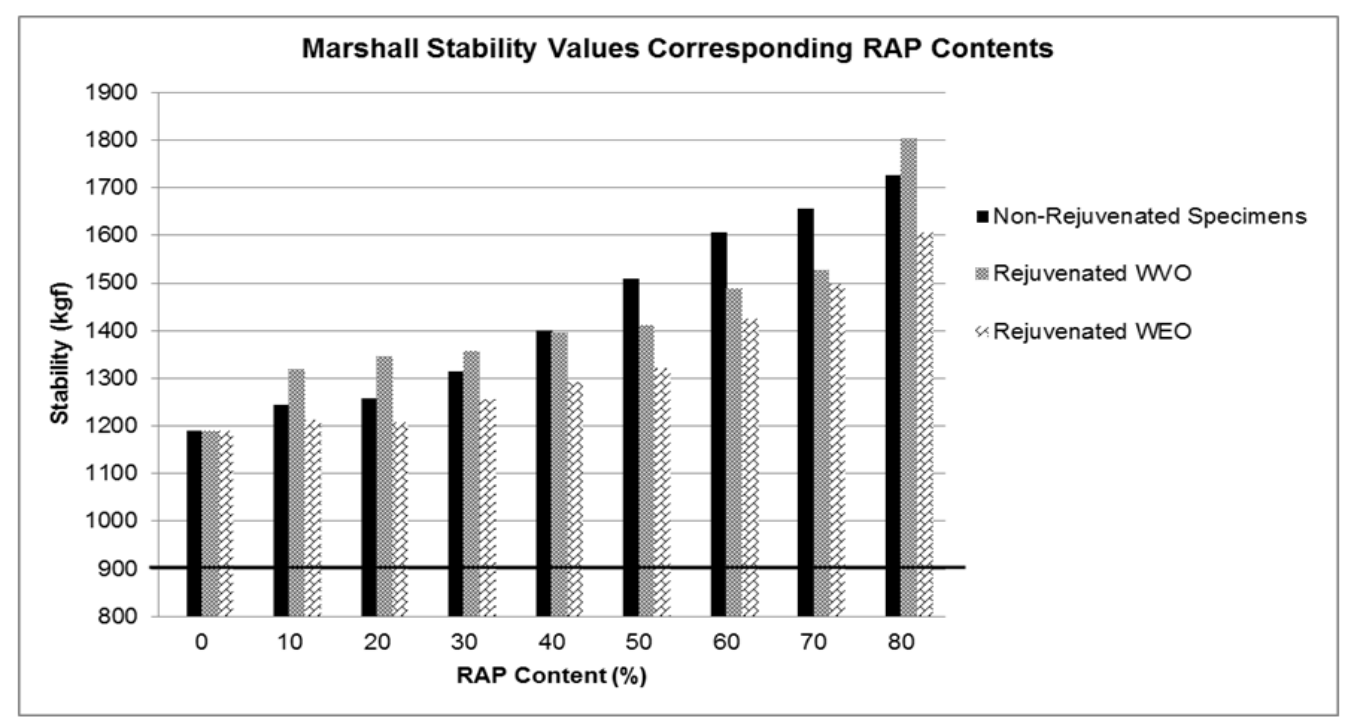

Fig. 3: Marshall stability values.

When evaluating flow rates, it is understood that this criteria is determinative for both non-rejuvenated and rejuvenated RAP involving mixtures. It is seen that, mixtures containing over $20 \%$ of non-rejuvenated RAP almost fail to meet the flow rate criteria since WEO and WVO rejuvenated mixtures performed better in terms of flow. Flow rates however, has been decisive in determination of maximum possible amount of rejuvenated RAP within type I wearing course as per Turkish specifications. In this sense, $70 \%$ of rejuvenated (WEO modified) RAP can be employed within type I wearing course since on the other hand, $80 \%$ of WVO rejuvenated RAP can be implemented. It is obvious that the amount of maximum RAP which can be implemented without failing to meet all Turkish criteria increases substantially by rejuvenation process with these rejuvenating oils. Evidently, 50\% and 60\% more RAP can be employed by .use WEO and WVO respectively. In terms of maximum amount of RAP, WVO accomplished $10 \%$ more content than WEO due to its high resistance against temperature. 


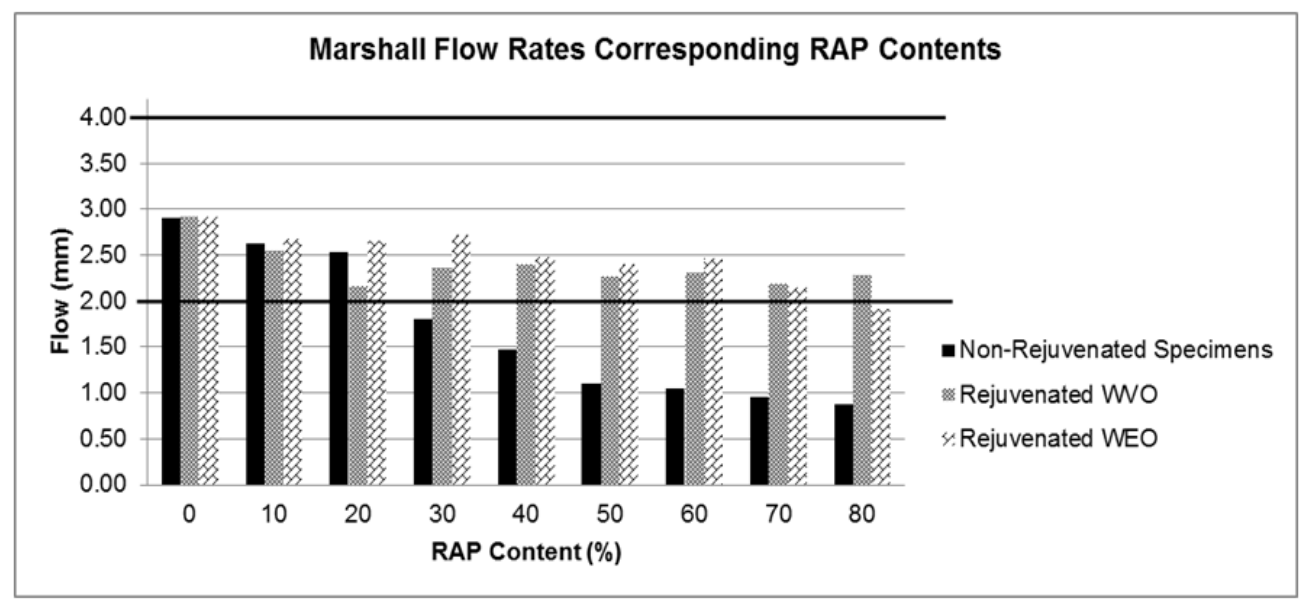

Fig. 4: Marshall flow rates.

\section{Indirect tensile strength results and aging indices}

Specimens prepared with 70\% RAP content for both rejuvenated and non-rejuvenated mixtures were tested for ITS. The test was also conducted on specimens prepared with virgin mixtures with no RAP content as control specimens. The results are shown in Fig. 5.

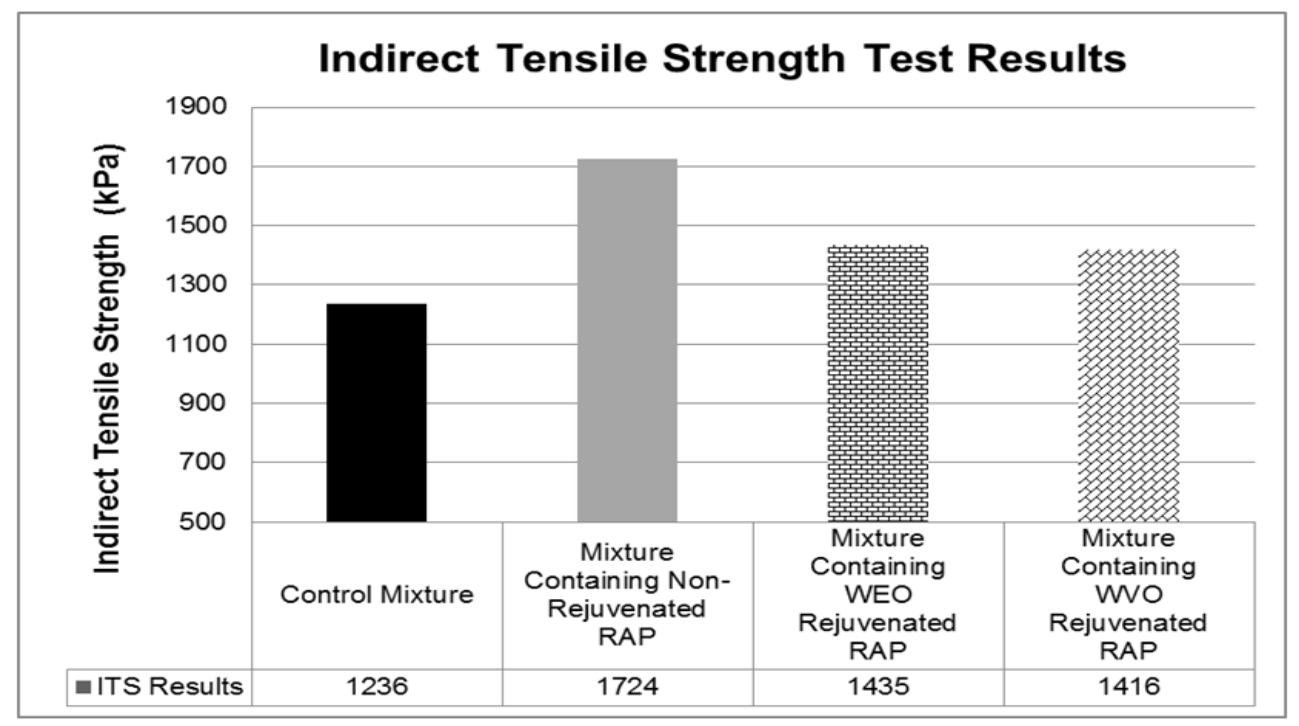

Fig. 5: Indirect Tensile Test Results.

ITS results provide an insight about the mixtures stiffness. It is seen that rejuvenated RAP recorded lower ITS than non-rejuvenated mixtures containing RAP materials. The use of WEO and WVO as a rejuvenator can soften the bituminous mixtures and give the mixtures a better workability; which will cause better flexibility. Aging indices based on ITS values were calculated as 1.39 for non-rejuvenated mixtures and 1.16 for WEO rejuvenated mixtures as well as 1.15 for WVO rejuvenated mixtures. The closer the aging index gets to 1, the less the mixture is stiffer. It can be concluded that the use of WEO and WVO can soften the mixtures containing RAP. WVO performed slightly better than WEO in terms of softening taking the aging indices into consideration.

\section{Conclusions}

Efficient deployment of resources should be managed in asphalt paving industry and real attention should be paid to the issue. Aggregate quarries and petroleum industry both consume natural resources to feed asphalt paving industry with raw materials. Sustainability should not remain in just study subjects but also it must become a social and institutional 
responsibility. Recycling is now possible with recent techniques and new technologies are introduced all along the time to industrial world. Reutilizing of aggregates and bitumen will save natural resources and accordingly the road construction costs to a large extent. In addition, recycling of RAP with waste oily additives will also be in favour of waste management. WEO and WVO additives as their name suggests are waste materials and are supposed to be recycled, reutilized or disposed.

Within the scope of this study, the influence of WEO and WVO rejuvenators on properties of RAP was investigated. It was found that, these rejuvenators as oily additives contribute actively taking the role of previously evaporated and/or separated oil constituents of aged RAP binder. The properties of RAP binder can be enhanced by use of WEO and WVO to fulfil specification requirements. Binder penetration and softening point values as well as viscosity of binder can be modified by optimum WEO and WVO contents. Penetration value is determinant in determination of optimum rejuvenator content. For any kind of rejuvenator available at the market, the selection process can be conducted in order to determine optimum content. In this study, 5.4\% of WEO by weight of binder and 5.1\% of WVO by weight of binder have been found adequate based on penetration values. It is recommended to perform supplementary tests in lights of Superpave standards and specifications. Rheological evaluation of rejuvenated binders can be more interpretive in terms of characterization of rejuvenated binder. Rejuvenated binder not only can fulfil desired properties, it is also capable of meeting after RTFOT requirements. It can be said that both WEO and WVO are substantial additives in rejuvenation of aged RAP binder.

Implementing WEO and WVO as rejuvenators makes it possible to involve high amounts of RAP within HMA wearing courses. By rejuvenation technology up to 70-80\% of RAP can be utilized without adverse effects (as per Turkish specifications) within the surface courses. Rejuvenated mixtures are convenient to process in terms of mixing and compaction. WEO and WVO convenient the compaction at standard HMA application temperature ranges. Investigations present that rejuvenated RAP mixtures are less brittle and more durable than non-rejuvenated RAP mixtures. Aging indices of rejuvenated mixtures are improved compared to non-rejuvenated mixtures. It is recommended to evaluate mechanical properties of rejuvenated RAP mixtures in accordance with Superpave criteria. Mixtures should be prepared by means of a gyratory compactor and evaluated for volumetric analysis. Supplementary performance based experiments should be conducted. For RAP mixture tests, rutting and fatigue performance evaluation are highly recommended as well.

\section{References}

[1] Asphalt Recycling and Reclaimin Association, Basic Asphalt Recycling Manual, U.S. Department of Transportation, 2001.

[2] K. R. Hansen, A. Copeland, Annual Asphalt Pavement Industry Survey on Recycled Materials and Warm-Mix Asphalt Usage, 2009-2012.

[3] I. Sonmez, A. Topcu, S. A. Yildirim, B. K. Eren, E. Gunay, M. Kara, B. Kavakli, "Recycling and reuse of old asphalt coatings in hot bituminous mixtures," in 24th World Road Congress, 2011.

[4] M. Tao, R. B. Mallick, "Effects of Warm-Mix Asphalt Additives on Workability and Mechanical Properties of Reclaimed Asphalt Pavement Material," Transp. Res. Rec. J. Transp. Res. Board. vol. 2126, pp. 151-160, 2009.

[5] W. Fernández-Gómez, "A review of asphalt and asphalt mixture aging," Ing. e Investig., vol. 33, pp. 5-12, 2013.

[6] D. Lesueur, "The colloidal structure of bitumen: Consequences on the rheology and on the mechanisms of bitumen modification," Advances in Colloid and Interface Science, vol. 145, pp. 42-82, 2009.

[7] J. C. Petersen, "Chemical Composition of Asphalt as Related to Asphalt Durability," Dev. Pet. Sci. 40, pp. 363-399, 2000.

[8] A. Dony, J. Colin, D. Bruneau, I. Drouadaine, J. Navaro, "Reclaimed asphalt concretes with high recycling rates: Changes in reclaimed binder properties according to rejuvenating agent," Constr. Build. Mater., vol. 41, pp. 175$181,2013$.

[9] J. Shen, S. Amirkhanian, J. Aune Miller, "Effects of Rejuvenating Agents on Superpave Mixtures Containing Reclaimed Asphalt Pavement," J. Mater. Civ. Eng., vol. 19, pp. 376-384, 2007.

[10] H. Asli, E. Ahmadinia, M. Zargar, M. R. Karim, "Investigation on physical properties of waste cooking oil Rejuvenated bitumen binder," Constr. Build. Mater., vol. 37, pp. 398-405, 2012.

[11] X. Yu, M. Zaumanis, S. dos Santos, L. D. Poulikakos, "Rheological, microscopic, and chemical characterization of the rejuvenating effect on asphalt binders," Fuel, vol. 135, pp. 162-171, 2014.

[12] M. Chen, F. Xiao, B. Putman, B. Leng, S. Wu, "High temperature properties of rejuvenating recovered binder with rejuvenator, waste cooking and cotton seed oils," Constr. Build. Mater., vol. 59, pp. 10-16, 2014. 
[13] A. Ongel, M. Hugener, "Impact of rejuvenators on aging properties of bitumen," Constr. Build. Mater., vol. 94, pp. 467-474, 2015.

[14] P. Nayak, U. C. Sahoo, "A rheological study on aged binder rejuvenated with Pongamia oil and Composite castor oil,” Int. J. Pavement Eng., pp. 1-13, 2015.

[15] M. Zaumanis, R. B. Mallick, L. Poulikakos, R. "Frank, Influence of six rejuvenators on the performance properties of Reclaimed Asphalt Pavement (RAP) binder and 100\% recycled asphalt mixtures," Constr. Build. Mater., vol. 71 538-550, 2014.

[16] X. Jia, B. Huang, J. A. Moore, S. Zhao, "Influence of Waste Engine Oil on Asphalt Mixtures Containing Reclaimed Asphalt Pavement," J. Mater. Civ. Eng., 04015042, 2015.

[17] J. Ji, H. Yao, Z. Suo, Z. You, H. Li, S. Xu, L. Sun, "Effectiveness of Vegetable Oils as Rejuvenators for Aged Asphalt Binders," Journal of Materials in Civil Engineering, D4016003, 2016.

[18] M. Gong, J. Yang, J. Zhang, H. Zhu, T. Tong, "Physical-chemical properties of aged asphalt rejuvenated by bio-oil derived from biodiesel residue," Construction and Building Materials, vol. 105, pp.35-45, 2016.

[19] Z. Sun, J. Yi, Y. Huang, D. Feng, C. Guo, "Properties of asphalt binder modified by bio-oil derived from waste cooking oil," Construction and Building Materials, vol. 102, pp. 496-504, 2016.

[20] V. P. Servas, A. C. Edler, M. A. Ferreira, E. J. Assen, "An Integrated Approach for Determining Additive Requirements in Hot Mix Recycling," in Sixth International Conference, Structural Design of Asphalt Pavements, Publ. Michigan Univ, Ann Arbor, 1987.

[21] J. Shen, Y. Ohne, "Determining Rejuvenator Content for Recycling Reclaimed Asphalt Pavement by SHRP Binder Specifications," Int. J. Pavement Eng., vol. 3, pp. 261-268, 2002.

[22] M. Zaumanis, R. B. Mallick, R. Frank, "Determining optimum rejuvenator dose for asphalt recycling based on Superpave performance grade specifications," Constr. Build. Mater. vol. 69, pp. 155-166, 2014.

[23] R. M. Anderson, D. W. Christensen, R. Bonaquist, "Estimating the rutting potential of asphalt mixtures using Superpave gyratory compaction properties and indirect tensile strength," in Association of Asphalt Paving Technologists Technical Sessions 2003, Lexington, USA, 2003, vol. 72.

[24] B. Sengoz, "The effect of asphalt film thickness on the aging and moisture susceptibility of hot mix asphalt," Istanbul Technical University, 2003.

[25] R. Y. Liang, S. Lee, "Short-term and long-term aging behavior of rubber modified asphalt paving mixture," Transp. Res. Rec., vol. 1530, 1996.

[26] A. Topal, B. Sengoz, "Effect of SBS polymer modified bitumen on the ageing properties of asphalt," in Proc. 4th Eurasphalt Eurobitume Congr. Copenhagen, Denmark, 2008.

[27] G. C. Hurley, B. D. Prowell. Evaluation of sasobit ${ }^{\circledR}$ for use in warm mix asphalt, Auburn, 2005. 